\title{
Desafios à Intervenção Interdisciplinar no Olhar da Equipe Multiprofissional em um Hospital de Referência em Tratamento de Câncer no Brasil
}

doi: https://doi.org/10.32635/2176-9745.RBC.2019v65n4.231

\author{
Challenges of the Interdisciplinary Approach under the Perspective of the Multidisciplinary Team in a Referral Hospital for \\ Cancer Treatment in Brazil \\ Desafíos del Enfoque Interdisciplinario a los 0jos del Equipo Multidisciplinario en un Hospital de Referencia para el \\ Tratamiento del Cáncer en Brasil
}

Karin Rejane Pichelli'; Marcia Valeria de Carvalho Monteiro²; Senir Santos da Hora ${ }^{3}$

Resumo

Introdução: A interdisciplinaridade é vista como uma alternativa que, somada ao desenvolvimento tecnológico, possa contribuir para a melhoria do cuidado em saúde, mas cuja construção é cercada de desafios. O Grupo de Estudos e Tratamento do Câncer Gástrico e Esofágico de um hospital referência em tratamento de câncer, composto por equipe multiprofissional, foi criado no sentido de promover interação entre a equipe e a melhoria no atendimento ao paciente, mas ainda precisa avançar no sentido da interdisciplinaridade. Objetivo: Conhecer e analisar os desafios à intervençáo interdisciplinar no olhar dos profissionais que integram a equipe. Método: Pesquisa qualitativa, cuja coleta de dados se deu por entrevista com profissionais das categorias inseridas no grupo e análise com base na hermenêutica-dialética. Resultados: O entendimento acerca do propósito do grupo e das temáticas integralidade e interdisciplinaridade, incluindo-se a percepção sobre a rede de cuidados ao paciente. Foram apresentados desafios objetivos e subjetivos, vinculados, respectivamente, à gestáo e à relação entre a equipe e entre os profissionais e os pacientes, para os quais é fundamental destinar o cuidado. Foram ainda apresentados avanços e resultados positivos e a necessidade de se direcionar o olhar também à equipe e ao seu cuidado. Conclusáo: Verifica-se a importância de levar os profissionais à reflexão acerca de sua intervenção, individual e coletiva, tendo em vista as possibilidades que estão ao alcance da equipe e de outras que poderiam ser alvo de pleitos e lutas para a efetiva implementação do Sistema Único de Saúde, como também valorizar as potencialidades e os ganhos já conquistados.

Palavras-chave: Equipe de Assistência ao Paciente; Integralidade em Saúde; Práticas Interdisciplinares.

\begin{abstract}
Introduction: The interdisciplinarity is seen as an alternative that, added to the technological development, could contribute to the improvement of healthcare, but whose construction faces challenges. The Gastric and Esophageal Cancer Study and Treatment Group of a referral cancer treatment hospital formed by a multi-professional team, was created to promote interaction between the team and the improvement of patient care; nevertheless, still needs to move towards interdisciplinarity. Objective: To know and analyze the challenges of interdisciplinary intervention through the vision of the professionals who belong to the team. Method: Qualitative approach, with data collected through interviews with professionals of the group's categories and analysis based on hermeneutic-dialectic. Results: One of the results was the understanding about the purpose of the group and the concepts of integrality and interdisciplinarity, including the perception about the patient care network. Other result was the presentation of objective and subjective challenges and their relation, respectively, to the management and relationship between the team, and between professionals and patients, for whom care is provided. In addition, it were presented positive results and progress, and the necessity to focus the attention to the team and its own care. Conclusion: It was verified the importance to encourage the professionals to think about their own individual and collective intervention, bearing in mind the possibilities that are within the scope of the team and others that could be the object of pledges and struggles for the effective implementation of National Health System and to value the potentialities and conquests already achieved.
\end{abstract}

Key words: Patient Care Team; Integrality in Health; Interdisciplinary Placement.
Resumen

Introducción: La interdisciplinariedad se considera una alternativa que, sumada al desarrollo tecnológico, puede contribuir a la mejora de la atención médica, pero cuya construcción está rodeada de desafíos El Grupo de Estudio y Tratamiento del Cáncer Gástrico y Esofágico de un hospital de referencia para el tratamiento del cáncer, compuesto por un equipo multiprofesional, fue creado para promover la interacción del equipo y mejorar la atención al paciente, pero aún necesita avanzar hacia la interdisciplinariedad. Objetivo: Conocer y analizar los desafíos de la intervención interdisciplinaria a los ojos de los profesionales que forman parte del equipo. Método: Investigación cualitativa, cuya recopilación de datos se realizó mediante entrevista con profesionales de las categorías incluidas en el grupo y el análisis basado en la dialéctica hermenéutica. Resultados: La comprensión sobre el propósito del grupo y los temas de integralidad e interdisciplinariedad, incluida la percepción sobre la red de atención al paciente. Se presentaron desafíos objetivos y subjetivos, vinculados, respectivamente, al manejo y la relación entre el equipo y entre profesionales y pacientes, para lo cual la atención es esencial. También se presentaron avances y resultados positivos, así como la necesidad de dirigir la mirada hacia el equipo y su cuidado. Conclusión: Existe la importancia de que los profesionales líderes reflexionen sobre su intervención individual y colectiva, considerando las posibilidades que están al alcance del equipo y otros que podrían ser el objetivo de reclamos y luchas para la implementación efectiva del Sistema Único de Salud, además de valorar el potencial y los logros ya alcanzados.

Palabra clave: Grupo de Atención al Paciente; Integralidad en Salud; Prácticas Interdisciplinarias.

${ }^{1}$ Instituto Nacional de Câncer José Alencar Gomes da Silva (INCA). Rio de Janeiro (RJ), Brasil. Orcid iD: https://orcid.org/0000-0002-7834-2188 ${ }^{2}$ INCA. Rio de Janeiro (RJ), Brasil. Orcid iD: https://orcid.org/0000-0002-3264-2994

${ }^{3}$ INCA. Rio de Janeiro (RJ), Brasil. Orcid iD: https://orcid.org/0000-0002-0161-3701

Endereço para correspondência: Karin Rejane Pichelli. Rua Gastão Poplade, 174, bloco 2, apto. 2 - Parolin. Curitiba (PR), Brasil. CEP 80220-160. E-mail: karin.pichelli@gmail.com 


\section{INTRODUÇÃO}

O câncer é uma questão de saúde pública e um dos principais responsáveis pelo adoecimento e óbito da população no mundo. Estima-se no Brasil, para os próximos anos, um aumento significativo dos casos ${ }^{1}$. Nesse contexto, o Sistema Único de Saúde (SUS) e as instituiçôes de prevenção, controle e tratamento de câncer precisam buscar estratégias de aprimoramento, considerando a complexidade desse processo de adoecimento. Soma-se ainda o contexto em que vem se dando a implementação do SUS - efetivação versus privatização - e a necessidade cada vez maior de gerir o cuidado.

Para Cecílio e Merhy², o cuidado integral acontece a partir da combinação de tecnologias de saúde. Tecnologias duras: equipamentos de imagem, radioterapia; tecnologias leve-duras: decorrentes de saberes estruturados que dirigem as intervençôes em saúde; e as tecnologias leves: processos inter-relacionais entre trabalhadores da saúde e entre estes e os pacientes. Assim, entende-se que as açóes precisam ir além do desenvolvimento tecnológico, mas que incidam na intervenção profissional, compreendendo o princípio da integralidade preconizado pelo SUS e instituído em seu arcabouço jurídico-normativo.

A integralidade foi definida com o objetivo de:

assegurar aos indivíduos a atenção à saúde dos níveis mais simples aos mais complexos, da atenção curativa à preventiva, bem como a compreensão, em sua totalidade, dos indivíduos/coletividades em suas singularidades ${ }^{3}$.

No âmbito do cotidiano das instituiçóes de saúde, a ação integral passa necessariamente pela construção interdisciplinar. A interdisciplinaridade é apontada como possibilidade de intervenção, visto que a ela possui uma concepçáo de totalidade, compreendendo o usuário/ paciente para além da doença ou de suas questóes objetivas. A interdisciplinaridade pode ser entendida como uma inter-relação entre conhecimentos, habilidades e competências; isto é, o fazer profissional baseado na reciprocidade e cooperação disciplinares ${ }^{4}$.

Uma proposta para potencializar a ação interdisciplinar no âmbito do SUS é a organização do trabalho em equipe, na qual são incluídas diferentes categorias profissionais, promovendo vínculo, acompanhamento, formulação de projetos terapêuticos, decisão conjunta, entre outros ${ }^{5}$.

Em outubro de 2015, na clínica de cirurgia abdominopélvica do hospital estudado, teve início o Grupo de Estudos e Tratamento do Câncer Gástrico, cuja proposta seria de integrar a equipe multiprofissional na organização do atendimento e discussão dos casos de pacientes matriculados para tratamento de câncer gástrico.
Semanalmente, além do atendimento inicial, eram realizadas reuniōes para discussão e definição de conduta dos casos em questão. Contudo, tais reunióes foram interrompidas no final do ano de 2017, retornando em maio de 2018, agregando também açôes de atendimento aos pacientes com tumores de esôfago. Embora tal espaço seja promovido no sentido de favorecer o diálogo e interação entre a equipe, entende-se como necessário avançar na construção de uma intervençáo interdisciplinar.

Para tanto, é fundamental conhecer as dificuldades de cada categoria e da equipe multiprofissional, para, a partir do conhecimento da realidade, analisar as possibilidades de se promover melhorias e açóes para que a interdisciplinaridade seja possível e se torne constituinte da intervenção junto aos pacientes e à sua rede de apoio ${ }^{4}$.

O presente artigo tem por objetivo analisar os principais desafios à intervençáo interdisciplinar, na abordagem ao paciente e à sua rede de apoio, a partir do olhar da equipe multiprofissional desse grupo de estudos e do tratamento do câncer gástrico e esofágico de um hospital de referência em tratamento de câncer no Brasil. A partir de tal problematização, tem-se o intuito de propor mudanças à qualidade dos serviços prestados, fortalecidos pela noção ampliada de saúde e pela valorização da interdisciplinaridade.

\section{MÉTODO}

$\mathrm{O}$ artigo tem caráter qualitativo para processamento e análise de informaçôes. De acordo com Guerra ${ }^{6}$, a pesquisa qualitativa é a mais adequada para a investigaçáo dos pontos de vista dos diferentes atores sociais, além de associar a empiria à sistematização do conhecimento, a partir do marco teórico-metodológico.

Foi realizada pesquisa de campo por meio de entrevista com os profissionais que integravam o Grupo de Estudos e Tratamento de Câncer Gástrico e Esofágico. O período de realização abarcou os meses de setembro a dezembro de 2018. Como critério de exclusão, três profissionais não participaram da pesquisa: um por ser orientador deste trabalho e os outros dois por licença médica e incompatibilidade de horários, tendo em vista o prazo estabelecido para coleta de dados. Ressalta-se, no entanto, que tal ausência não trouxe prejuízos à análise, visto que outros profissionais da categoria foram entrevistados.

O instrumento, de conteúdo semiestruturado, continha questôes fechadas para conhecimento e perfil dos entrevistados, e perguntas abertas, sendo oportunizado aos entrevistados falar livremente sobre o assunto proposto. Foi solicitada aos participantes autorizaçâo para gravar as entrevistas, com vistas a facilitar a apropriação das respostas e sem prejudicar a interação no momento da 
coleta. A entrevista foi norteada por roteiro previamente elaborado, sendo acrescentadas questóes que se fizeram necessárias para compreensão das respostas e opiniōes dos participantes.

Os dados coletados foram analisados no mês de janeiro de 2019, a partir da técnica hermenêutica-dialética que, de acordo com Minayo ${ }^{7}$, "consiste na explicação e interpretação de um pensamento". A dialética aborda as relaçôes historicamente construídas, dinâmicas, antagônicas e contraditórias entre classes, grupos e culturas. Dessa forma, objetivou-se alcançar não somente as questôes objetivas, mas também as subjetivas, que permeiam a construção histórica e dinâmica da realidade da qual se aproximam.

Para tanto, as entrevistas foram transcritas, lidas e ouvidas exaustivamente, pois, de acordo com $\mathrm{Minayo}^{7}, \mathrm{o}$ pesquisador, além de se apropriar dos dados apresentados, deve julgá-los, interpretá-los e tomar posição em relação a eles. Tanto o sujeito que comunica como aquele que o interpreta são marcados pela história, pelo tempo e pelo seu grupo.

As etapas que se seguiram foram: 1) organização dos dados: identificação do material coletado, leitura inicial e primeira associação dos dados apresentados; 2) classificação dos dados: a partir das questóes teoricamente elaboradas, foi feita seleção dos trechos mais relevantes, ideias centrais, que foram agrupados em categorias empíricas. Para tal agrupamento, foi considerada a relevância da fala acerca do objeto, recorrência do tema e expressividade; por fim, 3) análise final: movimento entre os conteúdos teóricos e empíricos, correlacionando-os, em um movimento dialético. Apesar da terminologia "final", toda a análise foi realizada no entendimento de que o produto é sempre provisório 7 .

Não há qualquer identificação dos participantes, os quais foram enumerados aleatoriamente, evitando assim sua exposição e garantindo o sigilo assegurado pelo Termo de Consentimento Livre e Esclarecido.

Cabe apontar que, para se chegar aos eixos principais do trabalho, viu-se como necessário trilhar um caminho anterior; isto é, para conhecer os principais desafios à interdisciplinaridade no Grupo de Estudos e Tratamento do Câncer Gástrico e de Esôfago, foi preciso apreender como os profissionais compreendem o grupo e de que forma entendem integralidade e interdisciplinaridade.

Assim, a primeira unidade de sentido contempla as concepçóes do objeto de estudo para cada participante: objetivos do grupo e entendimento acerca das temáticas de integralidade, interdisciplinaridade e rede de cuidados. A segunda unidade refere-se diretamente aos limites e desafios elencados pela equipe, os quais abarcam categorias empíricas relacionadas a questóes objetivas e subjetivas.

A pesquisa foi aprovada pelo Comitê de Ética em Pesquisa, sob o número CAAE: 91464218.0.0000.5274, conforme apontado na Resolução CNS/MS n. ${ }^{0} 510$ de 7 de abril de 2016.

\section{RESULTADOS E DISCUSSÃO}

Foram realizadas 11 entrevistas, nas quais foi possível contemplar todas as categorias profissionais que integram o grupo. A seguir, segue o quadro demonstrativo dos entrevistados, com dados acerca do tempo de formaçáo, tempo na instituição e tempo de participação no grupo.

Evidencia-se a composição do grupo como multiprofissional, apesar de uma grande parcela ser da categoria médica, reforçando a histórica hegemonia dos profissionais médicos nos ambientes hospitalares.

Contudo, o tempo de formação e de instituição pode ser contrabalanceado com o tempo de existência do grupo, de apenas três anos. Trata-se de uma experiência recente, considerando que a discussão da interdisciplinaridade

Quadro 1. Dados dos entrevistados

\begin{tabular}{|l|c|c|c|}
\hline \multicolumn{1}{|c|}{ Categoria profissional } & Tempo formação & Tempo de instituição & Tempo grupo \\
\hline Enfermagem & 10 anos & 5 anos & 3 anos \\
Enfermagem & 37 anos & 36 anos & 3 anos \\
Fisioterapia & 25 anos & 14 anos & 3 anos \\
Médico - cirurgião-oncológico & 17 anos & 14 anos & 3 anos \\
Médico - cirurgião-oncológico & 19 anos & 10 anos & 3 anos \\
Médico - cirurgião-oncológico & 18 anos & 14 anos & 3 anos \\
Médico - cirurgião-oncológico & 36 anos & 33 anos & 2 anos \\
Médico-oncologista & 17 anos & 13 anos & 1 ano e meio \\
Nutricionista & 24 anos & 13 anos & 2 anos \\
Psicologia & 45 anos & 7 anos & 3 anos \\
Serviço social & 18 anos & 16 anos & \\
\hline
\end{tabular}

Nota: Foram considerados diversos vínculos, desde residência, contrato etc. 
ganhou relevância, nas décadas de 1970 e 1980 do século $\mathrm{XX}$, contexto em que o Brasil vivia sob a égide da transição política. Um momento marcado por mobilizaçóes populares em favor da construção de um sistema de saúde, com as bandeiras: universalidade, equidade, integralidade da assistência, descentralizaçáo do poder e participaçáo popular ${ }^{8}$. Mesmo que esse movimento, denominado Reforma Sanitária, tenha culminado com a promulgação da Lei 8.080 e a criação do SUS, hoje fazem-se necessárias a reflexão sobre as dificuldades de sua efetivação, de apropriação de seus princípios, e a criação e implementação de alternativas que, associadas às tecnologias, oportunizem atenção e cuidado integral aos pacientes.

Em um segundo momento, os entrevistados foram abordados acerca de que forma chegaram ao grupo multiprofissional, sendo, para a maioria, por sua própria inserção na clínica e, alguns outros, por convite. É relevante ressaltar a permanência deles no grupo, o que reforça a importância e a validade dessa prática, inclusive como experiência profissional.

\section{CONCEPÇÕES}

\section{Objetivos do grupo: atendimento amplo e ágil}

Quanto ao entendimento dos propósitos do grupo, os profissionais o compreendem como um espaço de acolhimento do paciente, onde é oportunizado atendimento mais amplo e mais ágil, a partir do qual é possível a otimizaçáo do tratamento e seus resultados. Segundo eles, tais objetivos contribuem para a promoção da qualidade de vida ao paciente. Foi apontado como um espaço de comunicação entre profissionais e destes com o paciente e seu acompanhante, no sentido de prestar informaçóes e orientaçôes iniciais. Ainda, foi reforçado o intuito de promover pesquisas para maior qualificação das intervençôes.

Para um dos entrevistados, o grupo tem:

objetivos assistenciais, melhorar o fluxo dos pacientes, melhorar a qualidade de atendimento, acelerar o processo, vencer as barreiras todas que a gente tem, de exames, marcação de cirurgia... tentar promover a discussão dos casos, na reunião semanal, a ideia é discutir todos os casos que vão ser operados, a nível multidisciplinar... ideal é que a gente tenha cada um com a sua visão, pra gente tentar deliberar os casos do grupo... e a questão científica também. Tenta fomentar trabalhos científicos, artigos, pesquisas, levantar nossa casuística, fazer trabalhos prospectivos... Entrevistado 6

Os entrevistados afirmaram ter conhecimento da composição do grupo, sugerindo também a inserção de outras categorias e especialidades médicas. Seriam elas: oncologia clínica (que participa das discussões das segundas-feiras, mas não realiza atendimento inicial no grupo); fonoaudiologia; biomedicina e o Posto Avançado, um setor que funciona como elo junto à unidade destinada a pacientes em Cuidados Paliativos. Importante ressaltar que a inclusão do Posto Avançado é considerada relevante, tendo em vista que uma quantidade significativa de pacientes é matriculada com a doença em estágio avançado, e como não há uma proposta de tratamento que vise à cura, mas apenas controle de sintomas, estes são encaminhados à unidade de Cuidados Paliativos logo após a abertura da matrícula ou realização de exames para estadiamento da doença.

Os participantes apresentaram a demanda de estender o grupo para outras especialidades e setores que estâo diretamente relacionados ao processo de cuidado. Tal proposição remete às reflexôes trazidas por Merhy' ${ }^{9}$ Para a ampliação dos serviços, o autor aponta a necessidade de definir os espaços e relaçôes entre os vários atores envolvidos, ampliando os modos de produzir os atos em saúde, sem perder as eficácias de intervenção dos distintos profissionais.

\section{Integralidade e interdisciplinaridade}

As questôes que se seguiram diziam respeito à concepçáo do profissional acerca de integralidade na saúde e interdisciplinaridade. Sobre integralidade, alguns profissionais sentiram dificuldade em responder e de identificar as palavras que explicitassem o seu significado. Entre as respostas, cabe ressaltar as seguintes concepçóes: compreensão do paciente para além da doença; entendimento do paciente como um sujeito complexo; atendimento da atenção básica até a alta complexidade; oferta de uma assistência que contemple todos os níveis e aspectos do diagnóstico e do tratamento; contemplar a pessoa em todos seus aspectos da vida.

Nesse sentindo, percebe-se que, para essa equipe, integralidade tem vários conceitos, o que corrobora a compreensão trazida por Mattos ${ }^{10}$ de que integralidade é uma expressão polissêmica, que tem sido utilizada de múltiplas formas. O autor, em seus estudos, identificou três grandes grupos de sentidos para o termo, relativos: a) à organização da política de saúde, sobretudo das políticas específicas; b) ao modo de organização das práticas de saúde; c) e ao entendimento da "medicina integral"; ou seja, contrapondo-se à fragmentação do paciente.

Sobre interdisciplinaridade, os participantes da pesquisa trouxeram o entendimento de associação de ideias; trabalho realizado em harmonia para oportunizar o melhor ao paciente; disciplinas e especialidades voltadas a uma direção única; atendimento em conjunto; 
proximidade e integração; interação e comunicação entre a equipe; objetivo do alcance da integralidade, integração das várias visōes dos profissionais envolvidos na atenção ao paciente, conforme se segue:

é trocar visões, experiências, avaliaçôes e com isso decidir o que é melhor para aquele paciente que está ali com a gente; poder acolher mais o paciente e entender o que ele precisa. Entrevistado 9

Os depoimentos apontaram para o que afirma Severino ${ }^{11}$, de que a interdisciplinaridade, assim como a integralidade,

possui várias definições, entendimentos, concepções, mas que de alguma forma se aproximam do que vem a ser essa vinculação, essa reciprocidade, essa interação, essa comunidade de sentido ou essa complementaridade entre as várias disciplinas.

O autor afirma ainda que o conceito de interdisciplinaridade é algo desejado e buscado, mas ainda não atingido, seja na produção de conhecimento, na atividade de ensino, na pesquisa ou ainda na intervenção profissional.

\section{REDE DE CUIDADOS}

$\mathrm{Na}$ concepçáo do paciente como sujeito integral, para além de suas demandas diversas, há de se considerar que ele está inserido em determinado espaço, grupo, rede. Nas entrevistas, foi abordada a questão da rede de apoio, de cuidados do paciente. Todos os profissionais apontaram o quão importante é a participação e contribuição de um cuidador, acompanhante, não somente no atendimento do grupo, mas em todo processo de tratamento do paciente. Verifica-se, em algum nível, o processo de responsabilização desse acompanhante, sendo familiar ou não, atribuindo a ele o encargo na provisão de bem-estar.

Quando os pacientes vêm aqui, que têm familiar presente, que participa das decisôes, eu vejo uma evolução muito melhor desses pacientes, em relação àquele que não tem a família presente. Entrevistado 5

Pra mim, é um certo conforto ver que o sujeito tem alguém que tá indo com ele, se importando com ele... Entrevistado 11

Foi apontado que as pessoas de referência também necessitam ser acolhidas, entendidas como um sujeito integral, para as quais também há desafios, dificuldades, necessidade de organização do tempo e de recursos.
Eles adoecem tanto quanto (...) Esse familiar também tem que ser cuidado, senão, ele faz desgaste do cuidador. E pode começar, por estresse, a esquecer horário da medicação, data do exame... (...) Porque eles também trabalham, porque também têm filho, também têm seus problemas de saúde. Entrevistado 4

$\mathrm{Na}$ oncologia, na maior parte das vezes, a família acaba tendo um peso nesse cuidado muito maior que a própria instituição, na falta de políticas, na falta de suporte. Entrevistado 1

Isto é, para os participantes, a rede de cuidados tem sua importância no aporte emocional, financeiro ao paciente, relevante contribuição no processo de controle no tratamento, ao mesmo tempo em que precisa ser cuidada, de modo que sua sobrecarga náo comprometa o suporte dado que, de alguma forma, pode aliviar a carga de trabalho da equipe.

Identifica-se, nas falas dos entrevistados, a centralidade ocupada pela família no processo de cuidados, tendência observada pela literatura que aborda essa questão ao analisar as políticas sociais brasileiras nas últimas décadas. Nesse sentido, conforme apontam Mioto e Dal Prá ${ }^{12}$, a família é requisitada ao cuidado no domicílio, à participaçáo no tratamento, e passa a ser considerada parte fundamental no processo de cuidado, no sentido da sua responsabilidade, e por ser também objeto do cuidado.

Os entrevistados sinalizam a importância de se identificar a realidade vivenciada pelas famílias atendidas no grupo de estômago - seus limites, suas possibilidades - compreendendo que a falta de disponibilidade de membros da família para o cuidado, muitas vezes, reflete a forma de organização e configuração de cada família, assim como as condiçôes materiais de vida à que os membros familiares estão sujeitos.

\section{DESAFIOS E LIMITES \\ Estruturais: Gestão da Política de Saúde, do SUS e da Instituição}

Para os participantes, vários seriam os desafios para a intervenção interdisciplinar e o alcance da integralidade, desde questôes estruturais, passando pela gestão da instituição, organização e processos de trabalho, até questôes mais subjetivas e de relação interpessoal e interprofissional. Nos aspectos estruturais, os entrevistados sinalizam que algumas das grandes dificuldades de se proporcionar melhor atendimento ao paciente estão ligadas à gestão do SUS e da instituição.

O grande problema é o paciente chegar ao hospital, esse é o grande gargalo do nosso sistema de saúde. Entrevistado 5 
Foi mencionado por muitos o complicador de o paciente chegar à instituição com a doença em estágio avançado, razão pela qual:

acaba sendo mais importante o atendimento integral do que se o paciente viesse quase sem sintomas, com menos demandas. Entrevistado 9

Foram apontadas como causalidades desse agravante o funcionamento dos sistemas de regulação de vagas, como também o fluxo dentro do próprio sistema de saúde, no que diz respeito à realização de exames e atendimento com especialistas.

Em questão de sistema de regulação, o atraso e a dificuldade de marcação, a desinformação... Entrevistado 6

Em que pese os entraves advindos da operacionalização dos sistemas de regulação e suas implicações no processo de acesso do paciente aos serviços de saúde, há de se reconhecer a proposta de equidade e universalidade que fundamenta sua implementação. Ao serem instituídos pela Portaria número $1.559^{13}$, os sistemas de regulação têm entre seus objetivos: permitir a distribuição de forma equânime dos recursos de saúde para a população própria e referenciada; permitir a distribuição dos recursos assistenciais disponíveis de forma regionalizada e hierarquizada ${ }^{13}$.

Em contrapartida, Silva e Mendes 5 apontam que o desmonte do SUS acaba por contribuir para o subfinanciamento e a precarização do trabalho. Sua concretização permanece incompleta, tendo em vista os empecilhos e movimentos contrários para seu desenvolvimento. Complementam ainda, afirmando que o financiamento de saúde:

é incompatível com um sistema universal, sobretudo num país de dimensôes continentais, com grandes diferenças locais e regionais, e níveis dramáticos de desigualdades sociais e de concentração de renda.

A organização e a gestão interna da instituição também foram apontadas como entraves não descolados dos processos que interferem nas questóes macro da política de saúde, mas que se colocam mais próximos da realidade do grupo. Com relação ao aspecto gerencial, são verificadas a insuficiência de recursos e a ausência de apoio à realização do grupo, que já têm trazido resultados positivos aos pacientes. São ainda apontadas limitaçôes na questão estrutural, salarial e de recursos humanos.

Eu vejo dois pontos centrais que são os nós críticos que não deixam esse tipo de trabalho ser realizado de forma plena. Estrutural, é insumos, leito para pacientes, tempo cirúrgico no centro cirúrgico, drogas, quimioterápicos, que eventualmente faltam. $\mathrm{O}$ outro é salarial, porque você não consegue ter o profissional totalmente dedicado à instituição. Entrevistado 7

Para o entrevistado 2, a questão estrutural também diz respeito à comunicação e estabelecimento de fluxos com os demais setores que estão diretamente ligados ao funcionamento do grupo e ao tratamento do paciente.

Eu entendo que estão faltando profissionais, eu entendo a nossa falta de material, mas acho que isso não deve ser motivo pro paciente ter o atendimento mais prolongado. $\mathrm{Na}$ época, a gente não marcava exame de sangue, o paciente chegava, por exemplo, na nutrição e já via a albumina dele, se já tava precisando de alguma coisa. Através do exame de sangue, o médico tinha um respaldo se precisava transfundir ou não, se o paciente tava sangrando ou não. Até o paciente fazer o exame de sangue, leva um tempinho. Até a próxima consulta, um outro tempinho. Então, se esse paciente tá precisando, por exemplo, de hemotransfusão, vai prolongar. Outra coisa, exame de imagem. Quando o tomógrafo tá funcionando, temos que ter a boa vontade de ficar marcando. Mas a gente não consegue marcar pra todo mundo. Cadê a questão do SUS do direito pra todos? Sendo que o câncer não tem essa história de urgência ou não urgência. Entrevistado 2

A morosidade devida ao subfinanciamento e a consequente precarização do sistema de saúde têm repercussão direta sobre a qualidade da atenção. Nessa perspectiva, Mattos ${ }^{14}$ aponta que, para o alcance da integralidade, é necessário englobar os diversos atores sociais que envolvem os indivíduos, o que ele denomina de "sistemas de saúde"; isto é, promover relaçóes entre diversos serviços, suas coordenaçóes e gestóes.

A partir dos apontamentos, percebe-se que os profissionais sentem a necessidade da integralidade dentro da própria instituição, ultrapassando os atendimentos dos profissionais. Isto é, uma maior integração e aprimoramento dos processos; ou seja, de tecnologias leve-duras.

Cecilio e Merhy $^{2}$ afirmam que uma das maiores sobrecargas do processo gerencial de um hospital é conseguir coordenar adequadamente esse conjunto diversificado, especializado, fragmentado de atores, cuidadores, que resulte em uma dada coordenação do cuidado. Merhy ${ }^{9}$ complementa ainda que os modelos de atenção devem saber explorar positivamente as relaçóes entre as diferentes dimensóes tecnológicas que comportam o conjunto das açôes de saúde ${ }^{9}$. 
Outra limitação diz respeito à falta, à insuficiência de recursos humanos, o que gera uma sobrecarga de trabalho, deixando os profissionais "sufocados pela assistência", não havendo tempo suficiente para se dedicarem também ao ensino e pesquisa.

Precisa trazer algumas coisas mais acadêmicas. Levantar mais nossos dados, retrospectivas para fazer artigos. Importante a gente conhecer o resultado, para melhorar a partir daí. Entrevistado 6

Além do desgaste, entendem que o quadro reduzido de profissionais também prejudica o tratamento do paciente. Há casos em que os profissionais não conseguem se fazer presentes no atendimento de sexta, e/ou na discussão dos casos na segunda-feira. Ainda, no que se refere ao acompanhamento desse paciente, as agendas ambulatoriais, de exames, ficam lotadas, fazendo com que o retorno seja mais distante do que o recomendado.

$\mathrm{O}$ que aconteceu foi que o grupo foi diminuindo o número de reunióes e a gente acabou ficando mais no atendimento. $\mathrm{O}$ atendimento também tá restrito a alguns profissionais. Nem sempre todos estão lá e nem sempre todos estáo podendo dar continuidade ao atendimento que precisa. Entrevistado 1

\section{Processo de trabalho}

A sobrecarga e a carência de estrutura (material, física e humana) incidem diretamente no processo de trabalho.

A gente fala muito mais nas discussóes, na burocracia, quando chega pra lidar com o doente, ninguém tem mais paciência, porque a pessoa pensa, de como resolver de maneira burocrática e tem que sentar e atender o doente (...) Aí não adianta você fazer 200 atendimentos por dia, você pode fazer, por um período. Depois você não aguenta mais. Aí você acaba não explicando as coisas direito pro paciente. Entrevistado 10

A frequência reduzida dos profissionais nas atividades do grupo, em especial, nas reunióes de discussão das segundas-feiras, como apontado anteriormente, e o foco no atendimento individual acabam por distanciar os profissionais do fazer interdisciplinar. Para os entrevistados, se faz necessário um movimento por parte dos profissionais inseridos no grupo.

Eu vejo que cada profissional tá na sua caixa, no seu atendimento. E a gente dialoga muito menos que antes sobre esse paciente. Entrevistado 1

Eu sinto falta nas reunióes, de que todas as categorias compareçam e participem ativamente (...) Eu sinto falta que as categorias ocupem esse espaço e discutam mais a coisa. Entrevistado 4

$\mathrm{Eu}$ acho que a frequência durante as reunióes, ela acaba sendo pequena... porque o que vai enriquecer a discussão é justamente essa diversidade. Entrevistado 6

Os depoimentos remetem à análise por Sampaio et al. ${ }^{15}$ que afirmam: "a interdisciplinaridade exige que cada especialista ultrapasse seus próprios limites, abrindo-se às contribuiçóes de outras disciplinas", ao mesmo tempo que preserva a autonomia das áreas de saber, pressupondo a socialização dos conhecimentos ${ }^{5}$.

\section{Esforço, comprometimento, dedicação: humanização do atendimento e atenção ao profissional}

Questôes subjetivas, como esforço e comprometimento individual, à guisa de exemplo, também foram apontadas como desafios para a construçấo da interdisciplinaridade do grupo.

Talvez a gente não tenha como não funcionar sem essas ideias de amor, harmonia, bem, integral... talvez a gente náo tenha como funcionar sem uma coisa que, de uma certa forma, dá uma direção pra gente. Entrevistado 11

Contudo, várias são as questôes que incidem nos profissionais, desde as questóes de inserção e processo de trabalho, mas também na formação e nas relações sócio históricas, interpessoais e interprofissionais.

Para o entrevistado 1, o principal desafio é o entendimento dos profissionais tanto acerca do significado da interdisciplinaridade, como também em relação ao cuidado integral. De acordo com sua opinião, a formação dos profissionais ainda é incipiente quanto à intervenção interdisciplinar. Além disso, não há uma busca, um interesse em se apropriarem dessa vivência.

É ter profissionais que sejam engajados, que tenham essa visão desde o início da formação. Entrevistado 9

Segundo Peduzzi et al. ${ }^{16}$, os modelos educacionais contemporâneos em saúde são predominantemente uniprofissionais, pautados na racionalidade biomédica, na qual identifica-se uma ênfase no domínio técnico-científico em detrimento da compreensão interdisciplinar, interprofissional, integral e da determinação social do processo saúde-doença. Segundo os autores,

tradicionalmente, a formação inicial dos profissionais em saúde ocorre de forma relativamente isolada, sem que sejam planejadas experiências específicas para promover o contato de estudantes de diferentes carreiras. 
Assim, não é de se estranhar que os profissionais se queixem de falta de conhecimentos e habilidades para o trabalho colaborativo, de modo que muitas vezes falham em integrar seus conhecimentos e expertise, em prejuízo da integralidade e da qualidade da atenção à saúde ${ }^{16}$.

Para Entrevistado 4, “o trabalho não é só braçal, é emocional também". Nesse sentido, o acolhimento, colocado como um dos objetivos do grupo, precisa contemplar "respeito e empatia" pelo outro, cuidado e atenção integral.

Às vezes não tem aquela atenção toda com o paciente, aí o paciente acaba chegando, e criticando: poxa, aquele profissional nem me olhou. Então acho que a questão de mais atenção pra assistir melhor o paciente de uma forma geral dentro do grupo. Ouvir também... eles chegam aqui cheios de dúvidas, chegam aqui querendo desabafar. Entrevistado 2

Diante do exposto, entende-se que o atendimento poderia ser mais humanizado, o que corroboraria o alcance da integralidade, no que concerne às relaçóes entre os diversos atores sociais envolvidos nesse processo: usuários, profissionais e instituições.

Para os usuários do SUS, a ação integral tem sido frequentemente associada ao tratamento digno, respeitoso, com qualidade, acolhimento e vínculo ${ }^{17}$.

Para Merhy ${ }^{9}$, há que se explorar a cooperação entre os diferentes saberes e capacitar os profissionais de saúde:

para atuar no terreno específico das tecnologias leves, modos de produzir acolhimento, responsabilizaçóes e vínculos? .

A necessidade de um maior comprometimento é uma questão apontada por diversos participantes, mesmo por aqueles que entendem que o grupo já caminha no sentido da interdisciplinaridade e da integralidade.

Eu acho que as pessoas têm que se conscientizar e participar cada vez mais. Entrevistado 5

Acho que a gente deve tentar fortalecer a reuniáo do grupo. Entrevistado 6

Por outro lado, também foi apontado pouco cuidado para com o profissional e a equipe, o "cuidar de quem cuida", seja por meio de encontros sociais que oportunizem a aproximação e a convivência, como também da espiritualidade. Entender o profissional também como um ser integral.
Às vezes a gente sai sobrecarregado daqui, fisicamente quanto mentalmente, a gente sai um pouco mais pesado. Entrevistado 8

Porque se você náo elabora, você deixa isso pra debaixo do tapete, isso vai aparecer de uma forma ou outra... burnout... não é só muito trabalho. É um tipo de trabalho que exige muito da gente. Entrevistado 11

Essa parte holística do profissional não é bem trabalhada (...) Você entender um pouco a história do outro facilita você entender algumas atitudes do colega e não do profissional. E aí, muitos dos conflitos do dia a dia são atenuados. Entrevistado 7

Quanto à sobrecarga do trabalho sinalizada pelos entrevistados, cabe mencionar as implicações do processo de intensificação laboral nas diferentes esferas da vida social. Para Dal Rosso ${ }^{18}$, do ponto de vista do sujeito trabalhador, a intensidade é um gasto excessivo do trabalho em um mesmo intervalo de tempo, que consequentemente estimula uma elevada tensão da força de trabalho. A intensidade, o ritmo acelerado no trabalho e o número excessivo de horas na jornada vêm impulsionando a precarização da saúde do trabalhador. A reestruturação produtiva no Brasil, somada à precarização das relaçôes de trabalho e à intensificação de esforços e ritmos, tem ampliado e agravado o quadro de doenças e riscos de acidentes nos espaços sócio-ocupacionais.

\section{Questões positivas e propostas para o avanço da experiência}

Mesmo diante dos entraves apontados, os profissionais apresentaram consideraçóes acerca dos avanços já conquistados pelo grupo e seus integrantes. Tais avanços se referem a um melhor conhecimento no que diz respeito às atribuiçôes dos demais profissionais, aos resultados obtidos junto aos pacientes, à definição e conduta de tratamento, à redução de sintomas e à melhoria das condiçóes de vida. Percebem açôes e reforçam que a comunicação entre os profissionais vem sendo mais frequente. De acordo com os autores ${ }^{4}$, é necessário que se exerça a comunicação, ainda que parcial, de modo que cada visão disciplinar ofereça uma contribuição peculiar no compartilhamento com outras.

A partir dos relatos, foi possível compreender que tais momentos estão contemplados no espaço de discussão do grupo, mas, em maior frequência, nos contatos entre os profissionais - geralmente de duas ou três categorias diferentes - de acordo com as demandas apresentadas.

Mesmo que a gente não faça $o$ atendimento junto, mas a discussão do caso, o retorno de outro profissional com olhar diferente, chamando atenção para nossa área, isso é bom. Entrevistado 8 
Como possibilidades, foram sugeridas discussóes dos casos pela equipe antes ou depois dos atendimentos das sextas-feiras, no sentido de se obter a síntese das primeiras impressóes, encaminhamentos com mais imperativos e no acolhimento dos profissionais acerca das situaçóes de maior complexidade.

Foi sugerido acompanhamento longitudinal do paciente, no decorrer de todo o tratamento; ou seja, integralmente. Por fim, todos os participantes afirmaram que a experiência do grupo se constitui como uma importante inciativa que pode ser reproduzida pelas demais clínicas, cirúrgicas ou não, da instituição de saúde.

\section{CONCLUSÃO}

A partir da experiência e dos resultados da pesquisa, conclui-se que o entendimento de integralidade e interdisciplinaridade transitam entre si. Entende-se que o objetivo deste estudo foi alcançado, a partir do momento em que foi possível elencar e analisar os desafios à intervenção interdisciplinar a partir das falas dos entrevistados. Mesmo que a soluçáo de alguns dos desafios esteja relacionada a questóes mais estruturais, não restringe o olhar da equipe para possibilidades que estejam ao seu alcance.

No que diz respeito à rede de cuidados, percebe-se a relevância dada pelas categorias, contudo, em todas as entrevistas, foi necessário provocar o assunto. Dessa maneira, acredita-se que seja imprescindível outro estudo direcionado a esse objeto.

Os entrevistados apontam algumas barreiras à interdisciplinaridade que traduzem alguns elementos do complexo campo das relaçóes institucionais, como: a inserção histórica de cada profissão na divisão sociotécnica do trabalho; cada especialidade forja uma maneira particular de ver, compreender e intervir na realidade; a organização do processo de trabalho, e as condiçôes de trabalho que também não contribuem para que seja possível a construção desse diálogo.

Além disso, a partir das colocaçóes, acredita-se que tenha sido uma forma de provocaçáo, junto aos profissionais, de oportunizar a reflexáo acerca de sua inserção e exercício profissional. A interdisciplinaridade aponta na direção de respostas não somente às necessidades básicas humanas, mas que se voltem para a questão do direito e do enfrentamento dos graves problemas sociais do país a que nenhum profissional isolado conseguirá responder.

Entende-se que a pesquisa apresenta limitaçóes, em especial no que diz respeito à insuficiência de artigos e estudos atuais sobre a temática, à inexistência de registro de outras práticas que poderiam oportunizar referências, comparaçóes e troca de experiências. Além disso, o grupo multiprofissional foi criado e está em funcionamento sem projeto e referenciais prévios, o que prejudica seu monitoramento e avaliação.

Defende-se que uma prática interdisciplinar é aquela que valoriza a integração dos saberes. Recuperar a complexidade do real, que tem sido ocultada pelo objetivismo e reducionismo, é uma importante estratégia para fazer com que as abordagens sejam também integradas, mais próximas da existência cotidiana e das demandas que se apresentam. Há necessidade de construçấo de uma postura interdisciplinar que busque reconstruir as várias dimensóes que constituem a vida dos sujeitos.

\section{CONTRIBUIÇÕES}

Karin Rejane Pichelli colaborou na concepção, delineamento, coleta, análise dos dados, redaçáo do artigo e aprovação da versão a ser publicada. Marcia Valeria de Carvalho Monteiro orientou e colaborou na concepção, delineamento, análise, redação do artigo e aprovação da versão a ser publicada. Senir Santos da Hora coorientou e colaborou na concepçáo, delineamento, análise e redação do artigo e aprovação da versão a ser publicada.

\section{DECLARAÇÃO DE CONFLITOS DE INTERESSE}

Nada a declarar.

\section{FONTES DE FINANCIAMENTO}

Não há.

\section{REFERÊNCIAS}

1. Instituto Nacional de Câncer José Alencar Gomes da Silva. Estimativa 2018: incidência de câncer no Brasil. Rio de Janeiro: INCA; 2017.

2. Cecilio LCO, Merhy EE. A integralidade do cuidado como eixo de gestáo hospitalar. In: Pinheiro R, Mattos RA, organizadores. Construção da integralidade: cotidiano, saberes e práticas em saúde [Internet]. Rio de Janeiro: IMS ABRASCO; 2003 [acesso 2019 fev. 1]; p.197-210. Disponível em: https://docplayer.com. br/11198473-A-integralidade-do-cuidado-como-eixoda-gestao-hospitalar.html.

3. Ministério da Saúde (BR). Portaria no 545, de 20 de maio de 1993. Estabelece normas e procedimentos reguladores do processo de descentralizaçáo da gestáo das açóes e serviços de saúde, através da Norma Operacional Básica - SUS 01/93. Diário Oficial da União, Brasília, DF; 1993 maio 24. Seção I, p. 6961. 
4. Teixeira MJO, Nunes ST. A interdisciplinaridade no programa de saúde da família: uma utopia? In: Bravo MIS, Vasconcelos AM, Gama AS, et al. Saúde e Serviço Social. 5. ed. São Paulo: Cortez; 2012. p. 117-132.

5. Silva LB, Mendes AG. Serviço Social e a Interdisciplinaridade: algumas questôes para o debate. In: Silva LB, Ramos A. Serviço social, saúde e questôes contemporâneas: reflexôes críticas sobre a prática profissional. Campinas: Papel Social; 2013. p. 49-83.

6. Guerra ELA. Manual de pesquisa qualitativa. Belo Horizonte: Grupo Ănima Educação; 2014.

7. Minayo MCS. O desafio do conhecimento: pesquisa qualitativa em saúde. 7. ed. São Paulo: Hucitec; 2000.

8. Bibliotera Virtual Sérgio Arouca [Internet]. Rio de Janeiro: Fiocruz; [data desconhecida]. Reforma Sanitária. [acesso 2019 abr. 20. Disponível em: https://bvsarouca. icict.fiocruz.br/sanitarista05.html.

9. Merhy EE. Reflexōes sobre as tecnologias não materiais em saúde e a reestruturação produtiva do setor: um estudo sobre a micropolítica do trabalho vivo [tese]. Campinas: Faculdade de Ciências Médicas, UNICAMP; 2000.

10. Mattos RA. Os sentidos da integralidade: algumas reflexóes acerca de valores que merecem ser defendidos. In: Pinheiro R, Mattos RA, organizadores. Os sentidos da integralidade na atenção e no cuidado à saúde. 8. ed. Rio de Janeiro: CEPESC, IMS/UERJ, Abrasco; 2009. p. 43-68.

11. Severino AJ. Subsídios para uma reflexão sobre novos caminhos da interdisciplinaridade. In: Sá JLM, organizador. Serviço social e interdisciplinaridade: dos fundamentos filosóficos à prática interdisciplinar no ensino, pesquisa e extensão. São Paulo: Cortez; 1989. p. 11-21.

12. Mioto RCT, Dal Prá KR. Serviços sociais e responsabilização da família: contradiçôes da Política Social Brasileira. In: Mioto RCT, Campos MS, Carloto $\mathrm{CM}$, organizadores. Familismo, direito e cidadania: contradiçôes da política social. São Paulo: Cortez; 2015. P. 147-153.

13. Ministério da Saúde (BR). Portaria no 1.559 , de 1 de agosto de 2008. Institui a Política Nacional de Regulaçáo do Sistema Único de Saúde - SUS. Diário Oficial da União, Brasília, DF; 2008 ago. 4. Seção I, p. 48.

14. Mattos RA. Integralidade e a formulação de políticas específicas de saúde. In: Pinheiro R, Mattos RA, organizadores. Construção da integralidade: cotidiano, saberes e práticas em saúde. Rio de Janeiro: IMS ABRASCO; 2003. p. 45-59.

15. Sampaio CC et al. Interdisciplinaridade em questâo: análise de uma política de saúde voltada à mulher. In: Sá JLM, organizador. Serviço social e Interdisciplinaridade: dos fundamentos filosóficos à prática interdisciplinar no ensino, pesquisa e extensão. São Paulo: Cortez; 1989.

16. Peduzzi M, Oliveira MAC, Silva JAM, et al. Trabalho em equipe, prática e educação interprofissional. In:
Martins MA, Carrilho FJ, Alves VAF, editores. Clínica médica: atuação da clínica médica, sinais e sintomas de natureza sistêmica, medicina preventiva, saúde da mulher, envelhecimento e geriatria. Barueri: Manole; 2016. vol. 1.

17. González AD, Almeida MJ. Integralidade da saúde: norteando mudanças na graduação dos novos profissionais. Ciênc Saúde Coletiva. 2010;15(3):757-62. doi: http:// dx.doi.org/10.1590/S1413-81232010000300018

18. Dal Rosso SD, Cardoso ACM. Intensidade do trabalho: questôes conceituais e metodológicas. Soc Estado. 2015;30(3):631-50. doi: http://dx.doi.org/10.1590/ S0102-69922015.00030003

Recebido em 6/5/2019 Aprovado em 25/11/2019 